\title{
U.S. Health Care Expenditures
}

\author{
Gilbert Berdine MD
}

$\boldsymbol{P}_{\text {residential candidates are proposing Medicare }}$ For All or other forms of National Health Care for everyone in the United States. None of the proposals offers any specifics on how this care will be paid for. How much do we spend on health care in the United States? How does this sum compare with our ability to pay?

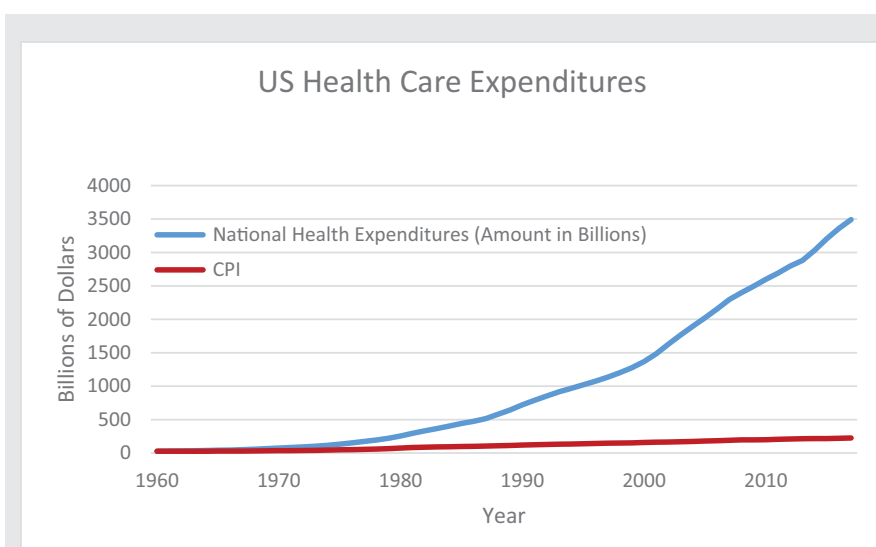

Figure 1

Figure 1 illustrates the growth of health care costs in the United States since 1960. National health care expenditures (NHE) were obtained from the Centers for Medicare and Medicaid Services (CMS). ${ }^{1}$ Consumer Price Index (CPI) data were obtained from the Federal Reserve. ${ }^{2}$ The CPI curve is scaled to the 1960 value for national health care expenditures. Figure 1 clearly shows that rising health care costs cannot be explained by inflation; NHE have increased from $\$ 27.2$ billion in 1960 to $\$ 3.492$ trillion for 2017. Medicare was enacted in 1964. Any program that substantially increases access to health care will necessarily have a price tag in the trillions of dollars per year.

Corresponding author: Gilbert Berdine Contact Information: Gilbert.berdine@ttuhsc.edu DOI: 10.12746/swrccc.v8i33.645

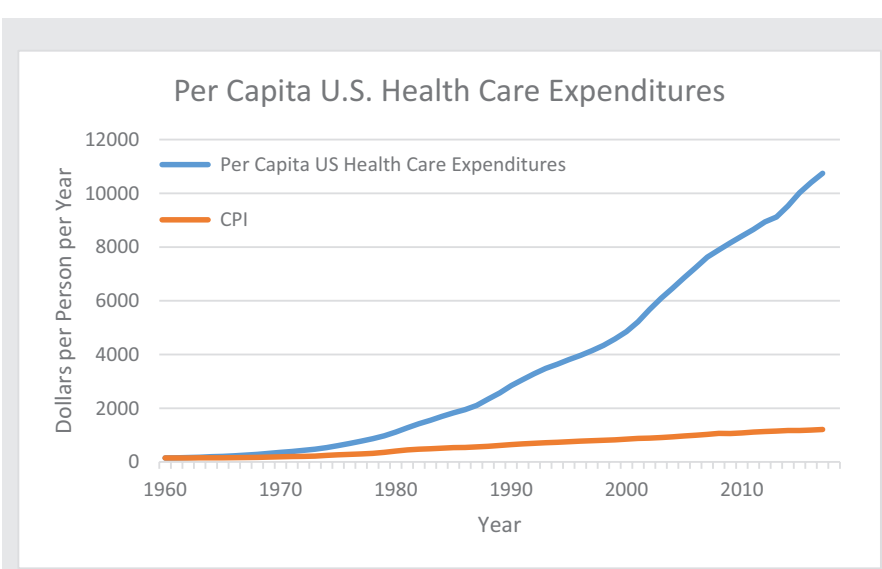

Figure 2

Figure 2 adjusts NHE for rising population; NHE were divided by U.S. population. Data on NHE and population were obtained from CMS. ${ }^{1}$ Figure 2 illustrates that rising health care costs cannot be explained on the basis of rising population. Figure 2 does not have a different shape from Figure 1. As was the case for Figure 1 , inflation cannot explain the rising costs. The average cost of health care has increased from $\$ 146$ per person per year in 1960 to $\$ 10,744$ per person per year in 2017. For a family of four, the 2017 cost would average almost $\$ 40,000$ per family per year.

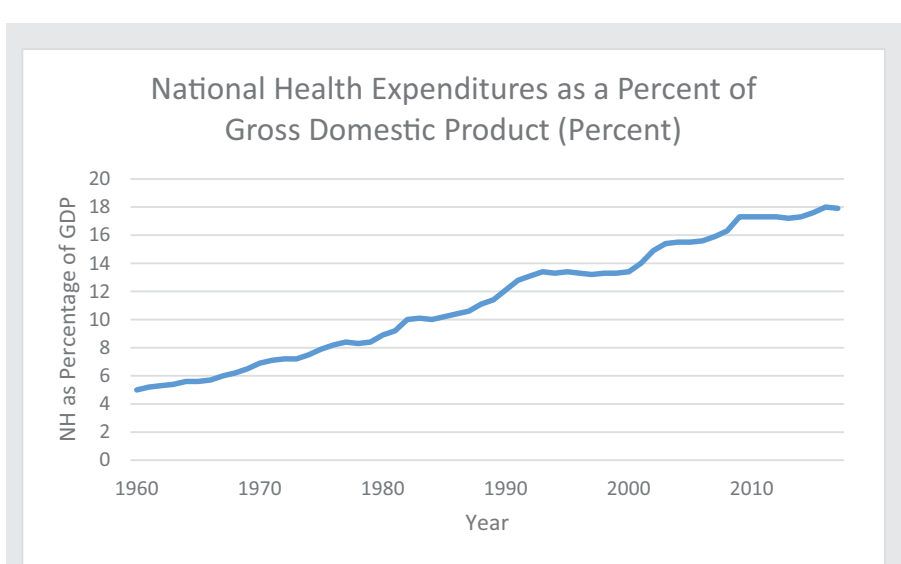

Figure 3 
Is U.S. health care affordable? One way to assess affordability would be to compare NHE to the total output of the nation. Figure 3 illustrates U.S. NHE as a percentage of U.S. GDP. This provides a gauge of whether the nation can afford the total cost of health care. National health care expenditures have risen from $5 \%$ of GDP in 1960 to almost $18 \%$ of GDP in 2017 and are one of the biggest items in the national budget, competing for resources with other big-ticket items such as defense and pensions (which include Social Security). What percentage is too much? That is debatable, but let us look at per capita expenses vs. per capita income.

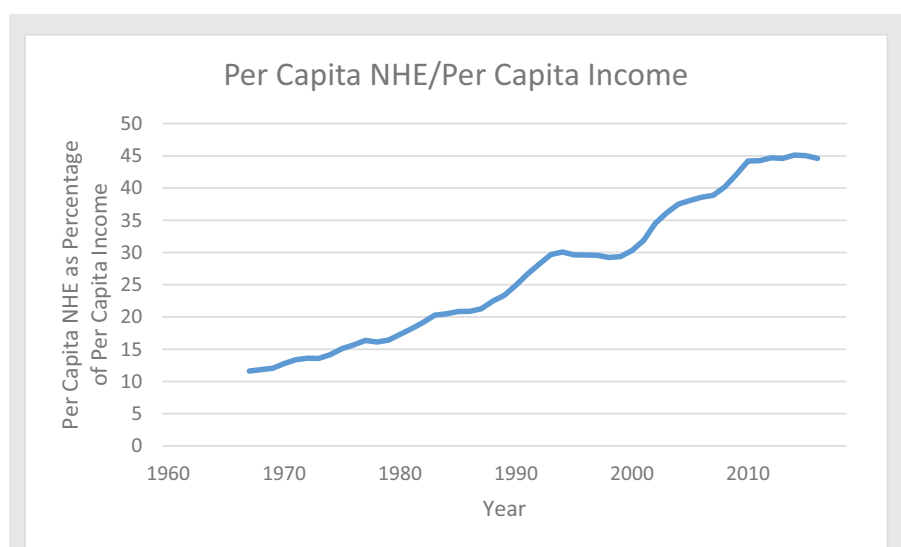

Figure 4

Figure 4 illustrates per capita NHE as a percentage of individual income. Per capita NHE data were from CMS. ${ }^{1}$ Median household income data were tabulated by a third party from census data. ${ }^{3}$ Average household size data were from census data. ${ }^{4} \mathrm{Per}$ capita NHE as a percentage of per capita income have increased from $11.6 \%$ in 1967 to $44.6 \%$ in 2016. This leaves half of the average income for everything else, including utilities, food, shelter, and clothing. It is doubtful that the median earner can afford more for health care. Any future increase in NHE will have to come from wealthy incomes, corporate income, trade surplus, or tax revenue. Tax revenue has been in deficit of current expenditures for some time and is likely to remain so. Trade has been in deficit for some time and is likely to remain so. Corporations are balking at higher costs for employer provided health insurance. The "rich" are a great target for political speeches, but whether or not they will pay for increases in NHE remains to be seen.

Keywords: health care expenditures, per capital costs, consumer price index

Article citation: Berdine G. U.S. Health Care Expenditures. The Southwest Respiratory and Critical Care Chronicles 2020;8(33):68-69

From: Department of Internal Medicine, Texas Tech University Health Sciences Center, Lubbock, Texas Submitted: 12/23/2019 Conflicts of interest: none

This work is licensed under a Creative Commons Attribution-ShareAlike 4.0 International License.

\section{REFERENCES}

1. National Health Expenditure Data-Historical. Centers for Medicare and Medicaid Services https://www.cms.gov/ResearchStatistics-Data-and-Systems/Statistics-Trends-and-Reports/ NationalHealthExpendData/NationalHealthAccountsHistorical.html. Accessed 12/24/2019.

2. Consumer Price Index, 1913. Federal Reserve Bank of Minneapolis. https://www.minneapolisfed.org/community/financial-and-economic-education/cpi-calculator-information/ consumer-price-index-and-inflation-rates-1913 .Accessed 12/ $24 / 2019$.

3. US Median Income by Year. https://www.multpl.com/usmedian-income/table/by-year. Accessed 12/24/2019.

4. Historical Households Tables. United States Census Bureau. https://www.census.gov/data/tables/time-series/demo/families/ households.html. Accessed 12/24/2019. 